\title{
The pathological effects of limited feeding in vasopressin-deficient animals
}

\author{
CYRILLA H. WIDEMAN and HELEN M. MURPHY \\ John Carroll University, Cleveland, Ohio
}

\begin{abstract}
Vasopressin-deficient rats and Long-Evans rats were subjected to one of the following treatments: (1) ad-lib access to food each day, (2) $23 \mathrm{~h}$ of food deprivation each day, or (3) $22 \mathrm{~h}$ of food deprivation each day. Vasopressin-deficient animals with 23 or $22 \mathrm{~h}$ of food deprivation survived for a significantly shorter period of time, had a greater decrease in body weight, and developed significantly more ulcers than the other subjects. Although vasopressin-deficient animals with $22 \mathrm{~h}$ of food deprivation consumed a higher percentage of food than vasopressin-deficient animals with $23 \mathrm{~h}$ of food deprivation, survival was not enhanced, body weight was not elevated, and ulceration was not ameliorated in these animals.
\end{abstract}

Animals deficient in vasopressin have been shown to be more susceptible to stress than normal animals. For example, Wideman and Murphy (1983) reported that vasopressin-deficient rats are more prone to stress ulcer formation under conditions of restraint and restraint plus intermittent shock than are normal animals. In addition, younger vasopressin-deficient animals have been shown to develop significantly more glandular ulcers than younger normal animals when subjected to $1 \mathrm{~h}$ access to food in the activity-wheel cage (Wideman \& Murphy, 1985). An unexpected finding in the latter study was that younger vasopressin-deficient rats in the home cage with $1 \mathrm{~h}$ access to food were significantly different from their normal control counterparts. The vasopressin-deficient rats had a shorter survival time and significantly more glandular ulcers than did the controls. The magnitude of these deleterious effects had not been previously reported in home-cage control animals.

The purpose of the present study was to determine whether a longer feeding period, namely $2 \mathrm{~h} /$ day, would prolong survival time and decrease the severity of ulcer formation in vasopressin-deficient animals.

\section{METHOD}

\begin{abstract}
Subjects
The subjects were 30 male homozygous Brattleboro rats and 30 male Long-Evans (LE) rats that were 5 weeks of age and weighed between 80 and $100 \mathrm{~g}$ at the time of their arrival at our laboratory. Brattleboro rats lack the hormone vasopressin, and are genetic mutants of the LongEvans strain. The Brattleboro rat has the pathological disorder known as diabetes insipidus; hence, it is commonly designated as DI. Both groups of animals were weighed and randomly divided into three subgroups of 10 animals each.
\end{abstract}

\section{Procedure}

All rats were individually housed in home cages. The animals were placed in alternating periods of light and

The authors' address is Department of Biology, John Carroll University, Cleveland, $\mathrm{OH} 44118$. darkness each day, with the lights going on at 8:00 a.m. and off at 8:00 p.m. Room temperature was maintained at $22^{\circ}-23^{\circ} \mathrm{C}$. Treatment groups were as follows: (1) adlib access to food each day, (2) $23 \mathrm{~h}$ of food deprivation each day, and (3) $22 \mathrm{~h}$ of food deprivation each day. All groups had ad-lib access to water each day.

All animals were habituated to their home cages for 7 days. On Day 8, 1 or $2 \mathrm{~h}$ access to food was introduced. The experimental or testing period was 9 days. Body weight, food intake, and water intake were recorded each day during both the habituation and experimental periods. Stomachs were examined for pathology following the expiration of the subjects during the testing period or following the sacrifice of subjects after the testing period. Glandular ulcers were defined as acute gastric lesions that were reddish brown in color. Some lesions were irregular and linear and tended to parallel folds of the glandular mucosa. Some lesions were circumscribed and focal. Statistical comparisons of the subgroups of rats were made by an analysis of variance (ANOVA). If statistical differences were found among the groups, ANOVA was followed by a protected $t$ test to determine significant differences among groups.

\section{RESULTS}

There were significant differences among the six subgroups with respect to mean days of survival, percent increase/decrease in body weight, percent increase/decrease in food intake, percent increase/decrease in water intake, absolute water intake, and mean length of glandular ulcers.

The results summarized in Figure 1 show that DI animals subjected to 22 or $23 \mathrm{~h}$ of food deprivation survived for a significantly shorter period of time than animals in the other four subgroups $(p<.01)$. Mean survival time for DI animals with $23 \mathrm{~h}$ of food deprivation was 5.0 days. For DI animals with $22 \mathrm{~h}$ of food deprivation, mean survival time was 6.3 days. In the other four 


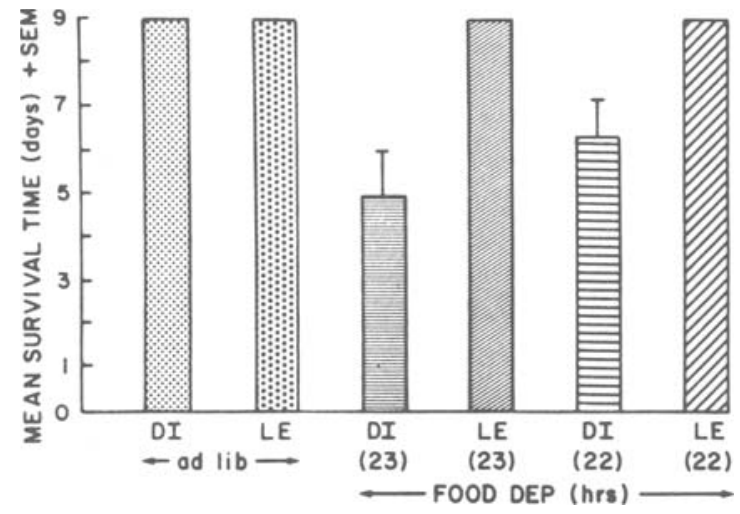

Figure 1. Mean survival time.

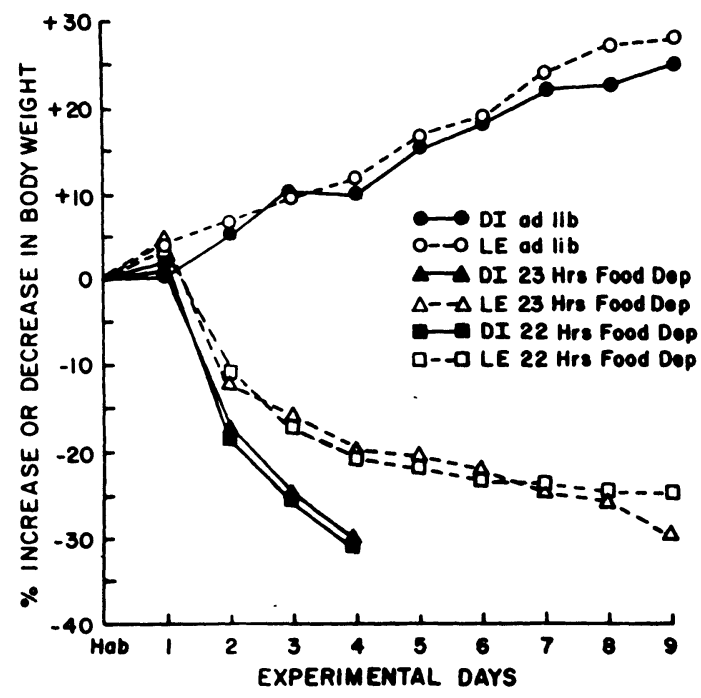

Figure 2. Percent increase or decrease in body weight throughout the experimental period as compared with the last day of habituation.

subgroups, all animals survived through the 9 experimental days. There was no significant difference between the DI 22-h food-deprived and the DI 23-h food-deprived animals.

Figure 2 shows the percent increase or decrease in body weight of the six subgroups throughout the experimental period as compared with the last day of habituation. Data for subgroups DI 22-h and DI 23-h food deprivation are not presented after Day 3 because some of the animals did not survive beyond this point. DI and LE animals with ad-lib access to food showed the same pattern of response. Therefore, under the condition of no stress (i.e., no food deprivation), the two sets of animals responded in a similar fashion: Both gained weight at approximately the same rate. The responses of LE animals with 22 and $23 \mathrm{~h}$ of food deprivation also paralleled each other; both lost weight in the same pattern. The responses of DI animals with 22 and $23 \mathrm{~h}$ of food deprivation were also similar. The fact that the two LE curves and the two DI curves follow the same pattern suggests that the 2-h feeding period made little difference in body-weight loss. If it had made a difference, one would expect the DI and LE curves for $22 \mathrm{~h}$ of food deprivation and the DI and LE curves for $23 \mathrm{~h}$ of food deprivation to be similar. It appears from these data that under both types of deprivation, the LE rats tended to undergo a more gradual weight loss than did DI rats. Differences between the DI and LE animals with both 22 and $23 \mathrm{~h}$ of food deprivation were significant at the .01 level.

Figure 3 shows the percent increase or decrease of food consumption of the six subgroups. The DI and LE animals given ad-lib access to food were again similar. In the case of food consumption in DI and LE rats with $22 \mathrm{~h}$ of food deprivation, the responses were quite similar. Given $2 \mathrm{~h}$ to consume food, rats quickly began eating a great deal of food and then this tendency leveled off. But, as seen in Figure 2, this seemed to have little effect on body weight. The curves for DI and LE rats with $23 \mathrm{~h}$ of food deprivation were also quite similar. Both DI and LE animals subjected to $22 \mathrm{~h}$ of food deprivation consumed a significantly higher percentage of food than did DI and LE animals subjected to $23 \mathrm{~h}$ of food deprivation on Days 2 and 3 of the experimental period $(p<.05)$. Again, the extra hour of feeding for DI rats had little effect on survival time or body weight.

Figure 4 shows the percent increase or decrease of water consumption of the six subgroups. The DI and LE animals given ad-lib access to food were once again similar. All food-deprived animals showed a dramatic decrease in water intake following the beginning of the experimental period. On Day 2 of the experimental period, the 23-h food-deprived animals (both DI and LE) showed a significantly greater percent decrease in water intake than did their 22-h food-deprived counterparts $(p<.05)$.

Absolute intake of water differed significantly among the six subgroups. Figure 5 summarizes these data. Dur-

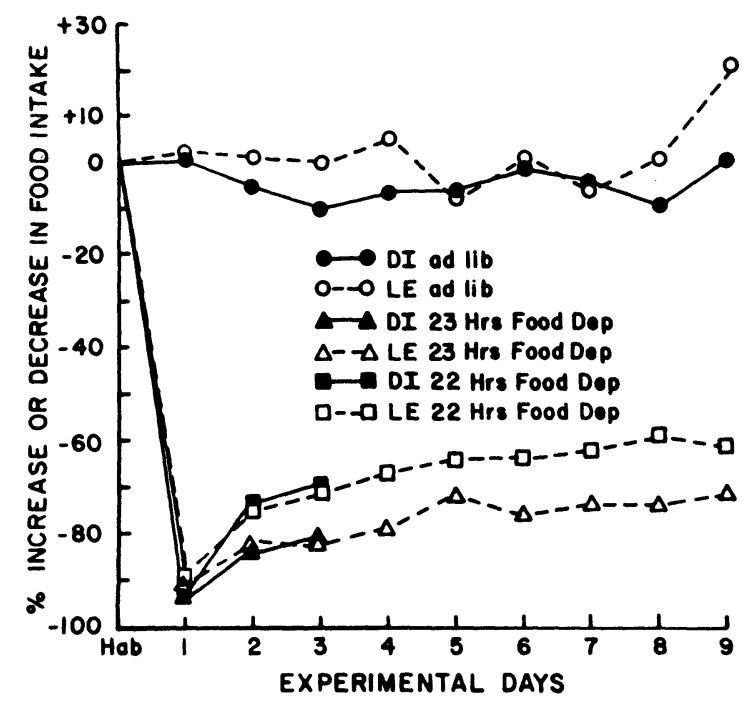

Figure 3. Percent increase or decrease of food consumption throughout the experimental period as compared with the last day of habituation. 


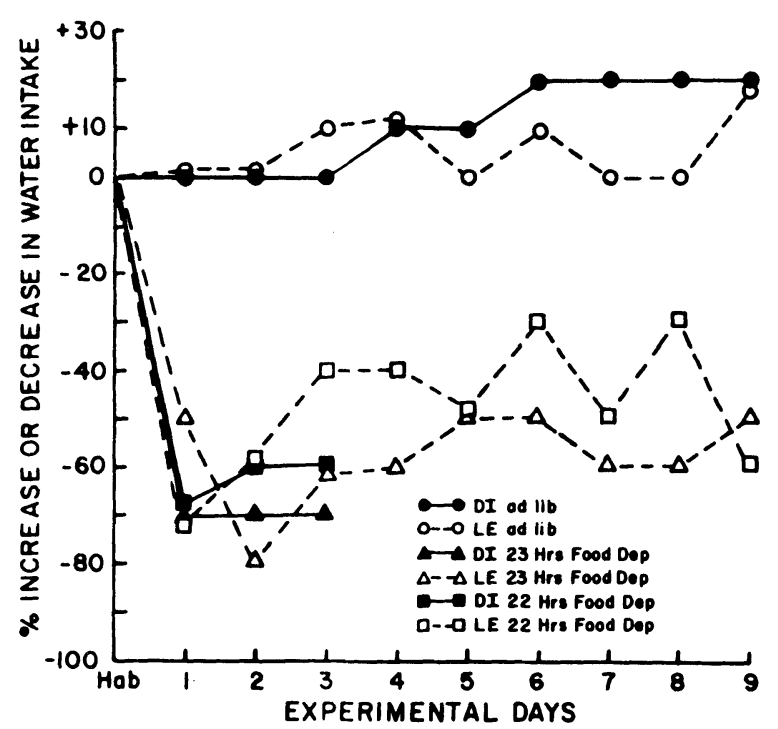

Figure 4. Percent increase or decrease of water consumption throughout the experimental period as compared with the last day of habituation.

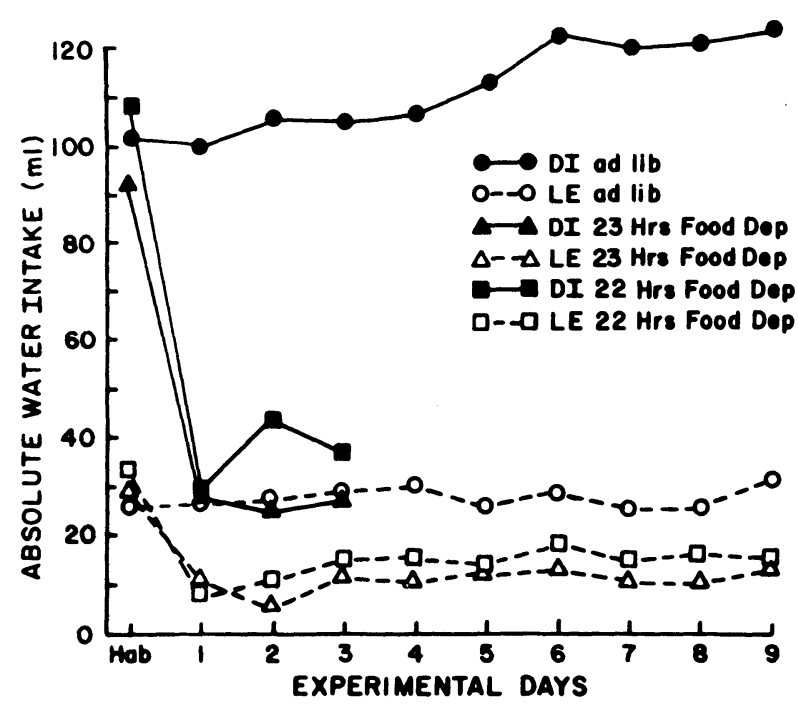

Figure 5. Mean absolute water intake on the last day of habituation and the experimental period.

ing the habituation period, all DI animals consumed significantly more water than did all LE animals $(p<.001)$. On Day 1 of the experimental period, all food-deprived animals significantly decreased their absolute water intake $(p<.001)$. On Days 1, 2, and 3 of the experimental period, DI 22-h food-deprived and DI 23-h fooddeprived animals consumed significantly more water than their LE counterparts $(p<.001)$. There were no significant differences between DI 22-h food-deprived and DI 23-h food-deprived animals. Neither were there any significant differences between LE 22-h food-deprived and LE 23-h food-deprived animals.

Animals in the food-deprived groups developed glandular ulcers in the stomach. Figure 6 summarizes the evaluation of the stomachs in all six subgroups. Animals (DI and LE) that were not food deprived did not develop stomach pathology. The mean total length of ulcers in the DI 23-h food-deprived group was $9.5 \mathrm{~mm}$; in the LE 23-h food-deprived group, $0.2 \mathrm{~mm}$; in the DI 22-h fooddeprived group, $6.7 \mathrm{~mm}$; in the LE 22-h food-deprived group, $0.6 \mathrm{~mm}$. The DI food-deprived animals (both 22 and $23 \mathrm{~h}$ ) had significantly more ulceration than the LE food-deprived animals $(p<.01)$. There were no significant differences between the DI 22-h food-deprived and the DI 23-h food-deprived animals. Neither were there any significant differences between the LE 22-h fooddeprived and the LE 23-h food-deprived animals.

In conclusion, we found that DI animals restricted to 1 or $2 \mathrm{~h}$ of feeding each day survived for a significantly shorter period of time than did DI animals given ad-lib access to food, LE animals given ad-lib access to food, and LE animals restricted to 1 or $2 \mathrm{~h}$ of feeding each day. These DI food-restricted animals also showed a significantly greater decrease in body weight and developed more stomach pathology than did the other animals. DI and LE animals with $2 \mathrm{~h}$ access to food consumed a significantly greater percentage of food than did DI and LE animals with $1 \mathrm{~h}$ access to food. However, the greater food intake of DI animals with $2 \mathrm{~h}$ access to food did not enhance survival time, elevate body weight, or decrease the severity of stomach ulceration.

\section{DISCUSSION}

Although the primary defect in the homozygous Brattleboro rat is the inability to synthesize vasopressin, other endocrine abnormalities are manifested in this animal as well (Sokol \& Zimmerman, 1982). Such differences from the normal condition may be secondary effects attributable to the lack of vasopressin and/or the state of diabetes insipidus itself. It has been suggested by some investigators that vasopressin may play a role in the activation of the hypothalamo-hypophyseal axis, because the DI rat has an impaired adrenocortical response to various stressors. If indeed this is the case, some of the results obtained in the present study could be explained on that basis. Further experimentation is neces-

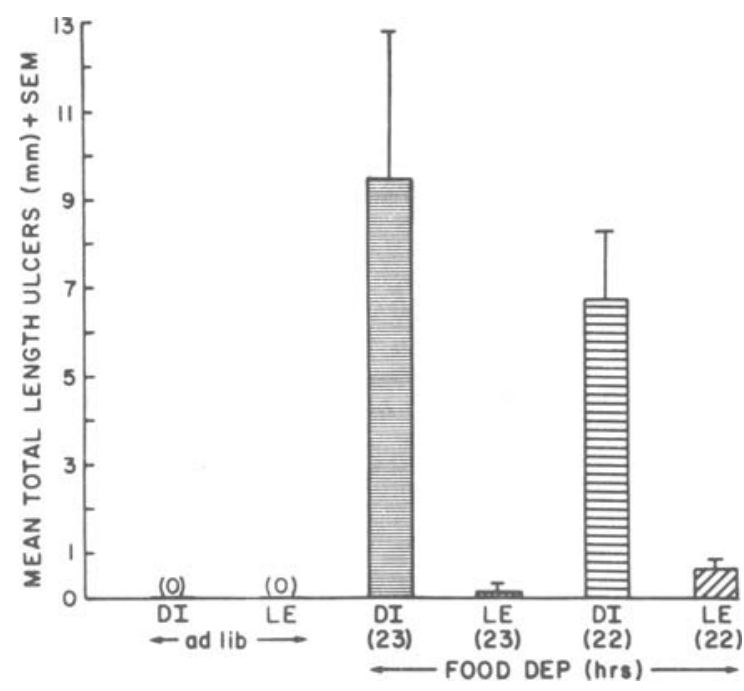

Figure 6. Mean total length of glandular ulcers. 
sary to elucidate the question of whether the observed peculiarities of DI rats obtained in this and other psychological experiments are caused merely by the absence of vasopressin, or whether they are consequences of the development of secondary changes in the absence of vasopressin.

\section{REFERENCES}

Sokol, H. W., \& Zimmerman, E. A. (1982). The hormonal status of the Brattleboro rat. Annals of the New York Academy of Sciences, 394, 535-548.
Wideman, C. H., \& MURPhy, H. M. (1983). The effects of restraint and restraint plus intermittent shock on ulcer formation in Brattleboro rats. Physiological Psychology, 11, 78-80.

Wideman, C. H., \& MURPHY, H. M. (1985). Effects of vasopressin deficiency, age, and stress on stomach ulcer induction in rats. Peptides, 6(Suppl. 1), 63-67.

(Manuscript received for publication December 23, 1985.) 